\title{
Girişimci Yenilikçi Üniversite
}

\author{
Gonca Telli Yamamoto \\ Maltepe Üniversitesi, İşetme ve Yönetim Bilimleri Fakültesi, İstanbul, Türkiye \\ ORCID: G.T. Yamamoto (0000-0002-8238-3185)
}

\begin{abstract}
Özet
Bu çalışmada girișimci ve yenilikçi üniversite kavram ve uygulamaları ele alınmakta girişimci ve yenilikçi üniversiteye yol açan koşullar ve gelişmeler üzerinde durulmaktadır. Çünkü üniversiteler toplumsal kalkınma açısından da büyük sorumluluk taşımaktadır. Devlet, sektör ve üniversite; işbirlikleri sağlama ve sorunlara çözüm getirme amacıyla yenilikçi ve girişimci üniversite yapısı arayışına girmişlerdir. Bu durum gelişmiş ve hatta sanayileşmiş toplumlarda daha hızlı görülmüștür. Bu çalıșmada girișimci ve yenilikçi üniversite kavram ve yapısı betimsel olarak mütalaa edilmektedir. Makalede gelişmiş batılı ülkelerdeki girişimci üniversite modelleri üzerinde durulmuş, girişimcilik, yaratıcılık ve yenilikçi üniversite kavramlarına değinilmiştir. Bu gelişmelerin ıșığında girişimci üniversite kavramı ve girişimci üniversite modelinin temelleri konuları tartıșılmıștır. Ayrıca temel konu girișimci üniversite olunca girișimci, üniversite ve ekonomik kalkınma kavramları çoğunlukla birlikte değerlendirildiğinden 2000'li yıllar sonrasındaki ekonomik kalkınma girişimcilik ve üniversite konulu bazı çalışmalar irdelenmiştir. AB ve ABD'deki farklılıklar kısmen ele alınmış kısaca araștırma ve patent konusunda üniversitelerin önemi üzerinde durulmuștur. Sonuçta ise girișimci ve yenilikçi bir üniversite olmak için gerekli unsurlar olan girişimcilik kültürünü geliştirme yönlü çabalar ve buna ilişkin üniversite yöneticilerinin destekleri olması gerekliliği ifade edilmiştir. Girişimci üniversite konusunda uygulamaların birden çok ve farklı düzeylerde gerçekleșebildiği vurgulanmıștır. Girișimci üniversite uygulamalarına yönelik olarak akademisyen, öğrenci, çalışan ve araştırmacılarının girişimcilik, yenilik veya yaratıcılık anlamında gelişimini sağlayabilir.
\end{abstract}

Anahtar Kelimeler: Girișimci Üniversite; Girișimcilik; Yenilikçilik; ekonomik kalkınma; model arayıșı

\section{Entrepreneurial Innovative University}

\begin{abstract}
In this study, entrepreneurial and innovative university concepts and applications are discussed and the conditions and developments leading to entrepreneurial and innovative universities are emphasized. Moreover, universities have a great responsibility in terms of social and economic development. In order to provide, an innovative and entrepreneurial university structure, government, industry and university collaborations has been delivered. This situation has seen more rapidly in developed and even industrialized societies. This study examines the concept and structure of an entrepreneurial and innovative university in a descriptive manner. The article focuses on entrepreneurial university models in developed western countries and the concepts of entrepreneurship, creativity and innovative university. In the light of these developments, entrepreneurial university concept and fundamentals of entrepreneurial university model are mentioned. In addition, since the main subject is the entrepreneurial university, the concepts of entrepreneur, university and economic development and some studies on economic development, entrepreneurship and university after 2000s were evaluated. The differences in the EU and the United States have been partially addressed, briefly emphasizing the importance of universities in research and patents. As a result, it has been stated that efforts to develop an entrepreneurship culture, which is essential for being an entrepreneurial and innovative university, and the support of university administrators related to this. It has been emphasized that practices on entrepreneurial universities can take place at multiple and different levels. An entrepreneurial university, can ensure the development of academics, students, employees and researchers in terms of entrepreneurship, innovation or creativity, in relation to practices.
\end{abstract}

Key words: Entrepreneur Universities; Entrepreneurship; Innovativeness; economic development; model search

\section{Giriș}

Dünyadaki hızlı gelişme ve ilerlemeler diğer klasik tarzda eğitim öğretim yapan eğitim kurumlarını olduğu gibi üni-

*Yazışma Adresi / Address for Correspondence:

G.T. Yamamoto, Email: goncatelli10@gmail.com

Geliş Tarihi / Received Date: 12.03 .2020

Kabul Tarihi / Accepted Date: 09.04.2020

Doi: $10.26701 /$ uad. 702735 versiteleri de etkilemiştir. Üniversiteler bilhassa 1990'lar sonrasında bilgi teknolojilerinin gelişmesiyle kendi durumlarını ve yapılarını tekrar gözden geçirmek zorunda kalmışlardır. Mevcut olan ve neredeyse günümüze kadar korunan sistemler altyapı bakımından 17. Yüzyıl hatta daha eskisine dayanan, bilgiyi koruyan ve minik parçalarla ancak damla damla sunan bir yapıdan gelmektedir. Oysaki bilgi toplumuna geçiş ve iletişimin ilerlemesiyle birlikte herkes kendini bir bilgi ve veri okyanusu içerisin- 
de bulmuştur.

$\mathrm{Bu}$ arayış içerisinde kısmen değişim yaşamış ancak çoğu birbirine benzer olan ve neredeyse şablon haline gelmiş olan üniversite yapılarıyla bu durumun sürdürülmesi giderek güçleşmektedir. Gerçekten de günümüzde bazı üniversitelerdeki programlar neredeyse birbirinin tıpatıp aynısı halinde hizmet sunmaktadır (Telli Yamamoto, 2018, s. 133) Bu da ne öğrenenler ne de toplumsal gelişme açısından yeterli bir gelişmeyi sağlayamamaktadır. Öte yandan toplumsal kalkınma açısından da üniversiteler sorumluluk taşımaktadır. O yüzden devletler, sektörler ve üniversiteler çözümü yenilikçi ve girişimci üniversite yapısına yönlendirmişlerdir. Hatta bu sorgulama gelişmiş toplumlarda daha hızlı bir öncelik haline gelmiştir. Bu yüzden girişimci ve yenilikçi üniversite kavram ve yapısını irdelemek için betimsel bir çalışma gerçekleştirilmiştir.

Bunu sağlamak için gelişmiş batılı ülkelerdeki girişimci üniversite modelleri üzerinde durulmuş, girişimcilik, yaratıcılık ve yenilikçi üniversite kavramlarına değinilmiştir. Buna göre girişimci üniversite kavramı biraz daha irdelenmiş ve girişimci üniversite modelinin temelleri üzerinde durulmuştur. Bunun yanında Girişimci Üniversite ve ekonomik kalkınma kavramları birçok yazar tarafından ele alındığı için 2000'li yıllar sonrasındaki ekonomik kalkınma girişimcilik ve üniversite konulu bazı çalışmalar ele alınmıştır. AB ve ABD'deki farklılıklara kısmen değinilmiş ve araştırma ve patent konusunda üniversitelerin önemi bir kez daha vurgulanmıştır. Sonuçta girişimci ve yenilikçi üniversite olmak için gereken unsurlar sıralanmaya çalışılmıştır.

\section{GIRIŞiMCILIK, YENILIKÇiLIK VE KURUMSAL DÖNÜŞÜM}

Girişimci üniversite konusunu Avrupa açısından ele alan Clark (1998) eğitim-öğretim ve bilimsel araştırmaların yanında akademik kültür ile piyasa kültürü arasındaki dengeyi koruyarak girişimcilik kültürünün üniversitelere entegre edilmesinin gerekliliği ve buna bağlı bir dönüşümü savunmaktadır. Savunduğu modele göre başarılı kurumsal dönüşümün beş ortak unsuru aşağıdaki gibidir (Clark, 1998):

(1) güçlendirilmiş bir itici güç

(2) genişletilmiş gelişmeye açık çevre

(3) çeşitlendirilmiş bir fonlama tabanı

(4) teşvik edilmiş bir akademik temel ve

(5) entegre bir girişimcilik kültürü.

Clark (1998) bu çalışmasında "Girişimci” olarak tüm üniversiteleri ve bunların iç bölümleri olan araştırma merkezleri, fakülteler ve okulları sosyal sistemler olarak değerlendirir ve bu yapıda bir girişimci üniversitenin kendi başına, işiyle ilgili gidişatında aktif olarak yenilik yapmaya çalışan yapıda bir üniversite olması gerektiğini tarifler. Bu bağlamda Girişimci Üniversite, yenilikçi olmakla kalma- yan ve yalnızca üniversite-sanayi işbirliğiyle sınırlandırılamayacak bir çağdaş üniversite modelidir.

Girişimcilik ve yenilikçilik çoğu zaman iç içe geçmiştir. Girişimcilik dendiğinde aşağıdaki fonksiyonlar akla gelmektedir (Güney, 2019):

- Yeni ürün veya hizmet üretimi ya da mevcut ürün hizmetlerin nitelik ve/veya kalite açısından yükseltilmesi

- Yeni üretim yöntemleri geliştirme veya uygulayabilme

- Sektöre yeni organizasyonlar kurma

- Yeni pazarlar kurma

- Yeni kaynak yaratma veya yeni kaynaklara ulaşma

Thurik ve Wennekers'e göre (1999), girişimcilik bireylerin yeni ekonomik fırsatları (yeni ürünler, yeni üretim yöntemleri, yeni organizasyon şemaları ve yeni ürün-pazar kombinasyonları) algılama ve yaratma konusunda, kendi başlarına, ekipler halinde veya mevcut organizasyonların içinde ya da dışında tezahür ettirme yeteneği ve istekliliğidir. Girişimciler belirsizlik ortamında ve çeşitli engeller karşısında kaynakların ve kurumların yeri, şekli ve kullanımı hakkında kararlar alarak fikirlerini piyasaya sunarlar.

Florida ise (2002) "yaratıcılı" terimini ele alarak ekonomik başarının anahtarı olarak görmektedir ve bir yaratıcı sınıfın oluşturulması konusuna değinmektedir. Yaratıcı ve Yenilikçi insanın oluşturulması ülkelerin bilgi stratejileri, çalışanlarda ve toplumda bulunan becerilerle ilgilidir. Ülkelerde büyümeyi teşvik etmek için yenilikçilik (inovasyon) yoğun veya ileri teknoloji firmalarını cezbetmek için alternatif stratejiler geliştirilmelidir. Bunda da liderlik görevi yukarıda sözü geçen devlet, üniversite ve endüstriye düşmektedir.

Cristensen ve Eyring (2011) "Yenilikçi Üniversite” başlıklı kitaplarında üniversitelerin gelecekteki başarıyı sağlamak için nasıl ve neden değişmesi gerektiğini değerlendirmektedir. Gerçekten de geçmiş yüzyılda geleneksel üniversiteler benzer işletme modellerine sahip diğer üniversiteler ya da yükseköğretim kurumları dışında ciddi bir rekabet yaşamamıştır. Ancak günümüzde üniversiteler de diğer sektörlerde olduğu gibi yıkıcı kar amaçlı rekabetle üniversite dışından farklı ortamlardan çeşitli saldırılarla karşı karşıya kalmaktadırlar. Geleneksel üniversiteler, bu yıkıcıların avantajlarını dengeleyebilecek değerli niteliklere ve kapasitelere sahip olmakla birlikte bu özelliklerini değerlendirerek yapıcı ve yaratıcı hale gelmek zorundadirlar.

Cristensen ve Eyring'de (2011, s.xi) "Yenilikçi Üniversite” isimli kitaplarında ABD'deki üniversite yapılarındaki anormalliği çözen üç faktör belirlemiştir. Bunlardan birincisi öğretmektir. Öğretim çok uzun zamanlar değişime uğramamakla birlikte çevrimiçi eğitim özelliklerinin karşı konulmaz cazibesi yıkıcı bir teknoloji olarak ortaya 
çıkmaktadır. Öğrenmeyi etkileyen farklı faktörlerin de etkisiyle yöntem ve yaklaşımlarda değişimler olması kaçınılmazdır. Buna en güzel örneklerden biri son yıllarda YouTube'ın bir öğrenme kanalına dönüşmesidir. Bir başka güncel örnek de 2019-2020 yıllarında dünyada görülen Covid 19 virüsünün yayılımı etkisiyle üniversitelerin öğretim yapılarını hızlıca yeniden gözden geçirmesi ve çevrimiçi konularındaki çalışmaların farklı bir bakış açısı kazanmasıdır. Bu konuda yapılan tartışmalarda öğretici ve öğrenenlerin adaptasyonu üzerinde ciddiyetle durulmaktadır (Lee, 2020). İkincisi ise öğrencilerin öğrenme zamanları çalışma koşulları gibi faktörler günümüzde sanayi toplumundan bilgi topluma geçişin etkisiyle, bir bakıma öğrencilerin yaşam tarzları ve iş anlayışları değiștiğinden üniversite yaşamı bilgi ve görgüsü konusunda ciddi bir yıkıcılık durumu söz konusudur. Üçüncüsü ise yükseköğretime yeni katılanlarla ayrılanlar arasındaki farktır. Yükseköğretime katılanların sayısı daha fazla ayrılanların daha az olması sebebiyle kamusal ruh hali dışında geçmişte daha derinlemesine ilişkiler gerektiren konuların yer alması gerektiğini savunmaktadırlar.

Bize göre girişimci ve yenilikçi üniversite insan, sistem ve yönetim açısından uygulamaları tarz ve yaklaşımlarında yenilik ve yaratıcılığı destekler unsurlar içeren bir üniversite yapısıdır. Konu sanayi üniversite işbirliği, AR-GE, Teknoloji Transferi, Teknoloji Transfer Ofisi (TTO), kuluçka merkezleri, start up gibi çeşitli kavram ve kurumları içinde barındırmakla birlikte gerek kendisinin insan kaynağını (akademisyen, çalışan, öğrenci) gerek devletin beklentilerini ya da sektörel beklentileri değerlendirmeye alan yapılar olarak düşülmelidir. Öte yandan sadece kendi içindeki girişimci ruhu taşıyan kişilerle (Öğrenci, Öğretim Elemanı, Araştırmacı, Çalışan vb) değil diğer girişimcileri de bir araya getirme kabiliyeti bulunan ve girişimcileri ve girişimciliği destekleyen üniversiteler akla gelmelidir.

Kısacası girişimci ve yenilikçi üniversite; kavram, görüş ve uygulamada yenilikçiliğe kucak açan ve bilimsel destekler sağlayan üniversite olarak da tarif edilebilir. Bu konuda öncü ya da takipçiliğin seçimi de üniversitelere kalmıştır. Girişimci ve yenilikçi üniversitelerde gerçekleștirilecek uygulamaların da kimi zaman kavramsal uygulamaların geliştirilmesi kimi zamanda doğrudan sorun çözmeye yönelik yaklaşımın izlenmesi gibi çeşitli seçenekleri bulunmaktadır.

\subsection{Girişimci Üniversite Modelinin Temelleri}

Girişimci üniversite modelinin temelinde de piyasanın ihtiyaç duyduğu niteliklerin, eğitim süresince öğrenenlere kazandırılabilmesi yatar. Ayrıca ürettiği bilgiyi ticarileştirebilen, gelir kaynaklarını çeşitlendirebilen, dinamik, rekabetçi, çevik ve işbirliği halinde, başarılı akademisyenler ve öğrencilerin ilgisini çekebilen bir sistematik yapı içermelidir. Bu durum aynı zamanda girişimci bir kültür de gerektirmektedir.

Aslında Clark (1998) bu değişim veya dönüşümle ilgili olarak birçok akademisyenin karı maksimize etmek iste- yen saldırgan iș odaklı insanlar olarak bireysel girișimciliğin verdiği olumsuz çağrışımlardan kaçındığı eleștirisini getirmektedir (s.4).

Bunun dışında üniversitelerin harekette çok ağır olduklarını ve aşağıdan yukarıya büyük bir direncin gelişebildiğinden de bahsetmektedir. Dönüşümün daha ziyade bir dizi bireyin üniversitenin temel birimlerinde ve bir üniversite öğretimi boyunca birkaç yll içerisinde bir araya gelerek, organize inisiyatifle kurumu yapılandırması ve yönlendirmesiyle sağlanabileceğini söylemektedir. $O$ yüzden girişimci ve yenilikçi liderliği sağlayabilecek ve inisiyatif alabilecek, yenilikçiliğe açık bir yönetim yapısına da ihtiyaç bulunmaktadır. Bunun için geleneksel yöntemlerin yanında yeniliklere ön veren bir yaklaşımın sergilenmesi gerekmektedir.

Clark'da (1998) çalışmasında girişimci üniversite kavramını girişimin -en çok özel aktivite ve enerji gerektirenkurumsal çaba manasında istekli bir çabanın temel taşlarını taşıyan bir kurum olarak görmektedir. Sonuçları şüphe olan yeni uygulamalar başlatırken risk almak ise önemli bir faktördür. Bu bağlamda daha hızlı, esnek ve özellikle artan ve değişen taleplere verilen tepkilere odaklanılmalıdır.

\subsection{Ekonomik Kalkınma, Girişimcilik ve Üniversite}

Girişimcilik ekonomik kalkınmanın en önemli mekanizmalarından biri olarak kabul edilir (Bunyasrie, 2010 içinde Schumpeter 1934 \& Landes 1998). Toplumsal büyüme, gelişme ve kalkınma açısından en önemli faktörlerden biri olan girişimcilik konusunun üniversite tarafından önemsendiği ve buna ilişkin çözüm arayışlarını içeren oldukça fazla sayıda çalışma bulunmaktadır. Özer'e göre üniversiteler sadece eğitim alanında hizmet vermekle kalmayıp teknoloji ve bilginin transferi konusunda ön plana çıkmış, piyasanın talep ve beklentilerini dikkate alan ve kalkınma sürecinde işbirliğinin ana unsurlarından biri haline gelmiştir (2018).

Etzkowitz ve Leydesdorff 1998'li yllarda değindikleri ekonomik kalkınma konusunu 2000'li yıllarda tekrar gözden geçirerek üçlü sacayağı olarak değerlendirmiş ve devlet, endüstri ve üniversite işbirliklerini ele almıştır. Erdoğmuş'a göre buna bağlı olarak bilgi tabanlı ekonomik sistemde, üniversiteler kilit kurumlar haline gelmekte hem beșeri sermayenin üretilmesinde hem de kurulan yeni işletmelerin gelişmesinde ve sanayinin katma değeri yüksek üretime yönlendirilmesinde vazgeçilmez bir unsur olarak devreye girmektedir (2013). İşgücünde yer alan büyüme kaynakları son zamanlarda insan sermayesi (eğitime bağlı), girişimcilik (çeşitli ölçülerde) ve yaratıcı sınıf (işçi meslekleriyle ilişkili) olarak görülmektedir (Faggian, Partridge, \& Malecki, 2016).

Carlsson ve arkadaşlarına göre bilgi üretiminde yıllar içinde ABD ve Avrupa arasında belirgin farklılıklar oluşmuştur (Carlsson, Acs, Audretsch, \& Braunerhjelm, 2009). Bu çalışmaya göre zaman içerisinde $A B D$ 'de üniversitelerde 
daha içselleștirilmiş kurumlar ekonomik kalkınmada destek verirken Avrupa'da bağımsız ve temel bilimler alanında yapılan çalışmalar makbul görülmüştür.

Yine Leydesdorf, Etzkowitz ve Kushnir (2015) Akademik Girişimciliğin Küreselleşmesi noktasına çekmiş ve Üniversite Patentlerinde Son Büyüme (2009-2014) Ayrıştırması konulu araştırmayı yapmıştır. Bu çalışmada Dünya Patent Pazarında akademinin ABD patentlerine katkısı giderek küreselleştiği ve 1998'den 2008'e kadar bir duraklamanın ardından, akademik girişimciliğin uluslararasılaşması ve ABD üniversite teknoloji transferinin devam etmesi nedeniyle, tüm patentlemelerin payında artış gösteren üniversite patent uygulamalarında uzun vadeli eğilim görüldüğü ifade edilmektedir. Dolayısıyla küresel ölçekte farklı araştırmacıların patent çalışmalarının belli merkezlere doğru yöneldiği de ifade edilebilir.

Roach'a (2017) göre bilimsel keşiflerin ticarileştirilmesini teşvik edecek, istihdam yaratmayı teşvik edecek ve üniversite araştırmalarına devlet yatırımlarına daha fazla getiri sağlayacağı ümidiyle üniversite kampüslerinde girişimci faaliyetler giderek daha fazla teşvik edilmektedir. Çalışmada, çeşitli alanlar ve üniversiteler arasında, üniversite araştırma laboratuvarlarında, girişimciliğe katılmanın teşvik edilmesinin ve sağlanan teşviklerin temel ve uygulamalı araştırma faaliyetleri, yayınlar ve buluş açıklamaları ile doktora öğrencilerinin kariyer ilgileri ve akademi ve girișimcilikte daha sonraki istihdam ile ne șekilde ilişkilendirildiğini araştırılmıştır. Ancak bir diğer yandan da temel araştırmalara olumsuzluğu olur mu yönünde sorular da önemsenmektedir. Kısacası girișimci ve yenilikçi üniversiteye dönüșüm araștırmalara farklılıklar getirirken bazı araștırmacıların piyasa dönük çalıșmaların getireceği yüzeysellik veya derine inememe gibi kaygıları Clark'ın (1998) görüșünü de desteklemektedir.

\section{SONUÇ}

Girişimci üniversite olmak için başta akademik camia olmak üzere üniversitelerin girişimcilik kültürü geliştirmesi yönlü bir çerçevede üniversite yöneticilerinin bu konuya ilişkin kararlı ve istekli uygulamalarının bulunmasını gerektirmektedir. Girişimci üniversite uygulamaları ise birden çok ve farklı düzeylerde gerçekleşebilmektedir. Bu çalışmalar bireysel girişimler olarak alt düzeyde yapılabileceği gibi sosyal ve toplumsal konulara yönelik geniş kapasiteli arge ve planlama çalışmaları ise çok disiplinli olarak gerçekleştirilebilir. Ayrıca ilgili kuruluş ve devlet ile yapılabilecek stratejik işbirlikleri de düşünülebilir.

Girişimci üniversite akademisyen, öğrenci, çalışan ve araştırmacılarının girişimcilik, yenilik veya yaratıcılık anlamında gelişimini sağlamaktadır. Bu bağlamda geliştirilebilecek yeni model ve uygulamalarla pazardaki talebin gelişimi takip edilerek ihtiyaç duyulan konuların belirlenmesi için gereken araștırma ve uygulamaya yönelik simülasyon (benzetim) vb çalışmaları altyapısı sağlanabilir. Ayrıca girişimcilerin akademisyenlerle, öğrenci veya araştırmacılarla bir araya gelip sorularını ortaya koyarak bu sorun veya arayışlara çözüm bulma ortamları sağlanabilir. Araștırma Laboratuvarları, teknoloji transfer ofisleri, kuluçka merkezleri gibi altyapı ve destek gerektiren çalışmaları desteklenebilir. Girişimciliğin sağlanabilmesi için akademisyen, öğrenci veya çalışanların kendi start uplarını kurmalarında yardımcı olunabilir. Yeni Pazar bulma ya da yeni kaynak yaratma alanlarında Devletin ilgili kurum ve kuruluşlarına destek olunup temel araştırmalar sunulabileceği gibi özel sektörün çalışmalarına yönelik çalışmalarda gerek altyapı gerekse uygulamaların ve sistemlerin oluşturulmasını sağlayacak stratejilerin de belirlenmesine ihtiyaç duyulmaktadır. Bunun yanında girişimci üniversiteler ekonomik kalkınmayı tetikleyecek insan sermayesi ve gerekli niteliklere sahip insan gücünü oluşturma yanında yeni meslek ve uygulamalara ilişkin yaratıcı sınıfın katma değer sağlamasına yönelik çalışmalara da yön veren kurumlar olarak görülmelidir.

\section{KAYNAKÇA}

Bunyasrie, V. (2010). The Role of Entrepreneurship on. Executive Journal. 03 10, 2020 tarihinde https://www.bu.ac.th/knowledgecenter/executive_journal/july_sep_10/pdf/aw23.pdf adresinden alındı

Carlsson, B., Acs, Z., Audretsch, D., \& Braunerhjelm, P. (2009). Knowledge Creation,Entrepreneurship and Economic Growth: A Historical Review. Industrial and Corporate Change, 18, 1193-1229.

Clark, B. (1998). Creating Entrepreneurial Universities: Organizational Pathways of Transformation. Issues in Higher Education. Pergamon.

Cristensen, C., \& Eyring, H. (2011). The Innovative University. San Francisco: Jossey Bass.

Erdoğmuş, Ş. (2013, 10). Girişimci Üniversite. 03 09, 2020 tarihinde http://girisimciuniversite.blogspot.com/2013/10/ girisimci-universite-girisimci.html adresinden alındı

Etzkowitz, H., \& Leydesdorff, L. (1998). Minerva: A Review of Science. Learning \& Policy, 203-208. doi:10.1023/A:1004348123030.

Faggian, A., Partridge, M., \& Malecki, E. (2016). Creating an environment for economic growth: creativity, entrepreneurship or human capital? Munich: MPRA. https://mpra.ub.uni-muenchen.de/71445 adresinden alındı

Florida, R. (2002). The Rise of the Creative Class (and how it's transforming work, leisure. community \& everyday life). New York: Basic Books.

Güney, S. (2019). Girişimcilik. Ankara: Siyasal Kitabevi.

Lee, K. (2020, 03 09). Coronavirus: universities are shifting classes online - but it's not as easy as it sounds. TheConversation. London. 03 11, 2020 tarihinde https:// theconversation.com/coronavirus-universities-are-shifting-classes-online-but-its-not-as-easy-as-it-sounds-133030?fbclid=IwAR1PCVVLCsoCX7XGPMynBy4mRO8Gcq2t19Hsg1qrwdmZ56RxSgNS-gwz7ws adresinden alındı

Leydesdorff, L., Etzkowitz, H., \& Kushnir, D. (2015, 12 14). The Globalization of Academic Entrepreneurship? The Recent Growth (2009-2014) in University Patenting Decompo- 
sed. 03 09, 2020 tarihinde https://arxiv.org/ftp/arxiv/papers/1512/1512.04214.pdf adresinden alındı

Özer, Y. (2018). Girişimci Üniversite ve Türkiye. Standart, 2025. https://statik.tse.org.tr/upload/tr/dosya/icerikyonetimi/9096/26062018161611-2.pdf adresinden alındı

Roach, M. (2017). Encouraging entrepreneurship in university labs: Research activities, research outputs, and early doctorate careers. PLoS ONE, 12(2). 03 09, 2020 tarihinde https://journals.plos.org/plosone/article?id=10.1371/journal. pone. 0170444 adresinden alındı

Telli Yamamoto, G. (2018). Türkiye'de Yükseköğretim Sistemi Üzerine Düşünceler. Üniversite Araştırmaları Dergisi, 132138. https://dergipark.org.tr/tr/pub/uad/issue/40777 adresinden alındı

Thurik, A. R., \& Wennekers, S. (1999). Linking entrepeneurship and economic growth. Small Business Economics, 13(1), $27-$ 55 